\title{
Neomycin C
}

National Cancer Institute

\section{Source}

National Cancer Institute. Neomycin C. NCI Thesaurus. Code C95127.

One of the two major active isomeric components of the neomycin complex. Neomycin

$\mathrm{C}$ is approximately half as active as neomycin $\mathrm{B}$. 